\title{
Concepção e avaliação de uma unidade de peneiramento forçado para a redução do tamanho de partículas presentes no esgoto bruto doméstico
}

\section{Design and evaluation of a forced sieving unit (FSU) for the reduction of the particle size present in raw domestic sewage}

\author{
Ana Raquel Teixeira \\ Doutora em Saneamento, Meio Ambiente e Recursos Hídricos pela Universidade Federal de Minas Gerais (UFMG) \\ Carlos Augusto de Lemos Chernicharo \\ Professor do Departamento de Engenharia Sanitária e Ambiental da UFMG
}

\begin{abstract}
Resumo
Este trabalho teve como objetivo a concepção e o teste de uma unidade de peneiramento forçado, utilizada para o pré-tratamento do esgoto bruto com vistas à redução do tamanho de partículas de matéria orgânica. A unidade de peneiramento forçado (UPF) era constituída de uma peneira metálica (abertura de malha de $1 \mathrm{~mm}$ ) inserida na tubulação de recalque através da qual o esgoto efluente era bombeado. O peneiramento forçado resultou em maior concentração de partículas com diâmetro entre 1,8 e 30 m, sem que houvesse retenção de material particulado. Todavia, a UPF não influenciou na redução/retenção de $\mathrm{DQO}_{\text {TOTAL }}$ do esgoto bruto.
\end{abstract}

Palavras-chave: pré-tratamento; peneiramento forçado; distribuição do tamanho de partículas; esgoto doméstico.

\section{Abstract}

The work focused on the conception and test of a forced sieving unit, used for the pre-treatment of raw sewage aiming at the reduction of organic matter particle size. The pre-treatment unit involved the use of a metallic sieve (1 $\mathrm{mm}$ cut-off) assembled inside the pipeline through which the influent sewage was pumped. The results indicated that the forced sieving resulted in a higher concentration of particles with range diameter between 1.8 and $30 \mu \mathrm{m}$, without the retention of particulate material. However, the forced sieving unit did not influence the reduction/retention of $\mathrm{COD}_{\text {TOTAL }}$ of the raw sewage.

Keywords: pre-treatment; forced sieving; particles size distribution; domestic sewage.

\section{Introdução}

A tratabilidade do esgoto sanitário em sistemas biológicos depende, dentre outros fatores, da distribuição de tamanhos de partículas (DTP), uma vez que frações solúveis e particuladas são suscetíveis a distintas reações bioquímicas (HU et al, 2002). Partículas biodegradáveis relativamente pequenas, em tese, são transportadas através da membrana celular em um curto período de tempo (HENZE et al, 1987), enquanto a matéria orgânica particulada biodegradável leva mais tempo para ser metabolizada, pois partículas maiores requerem uma hidrólise extracelular antes de seu transporte para o interior das células (HU et al, 2002).

A distribuição do tamanho de partículas dos esgotos influencia, também, os aspectos físicos dos reatores, uma vez que a dimensão das partículas influencia as taxas de sedimentação, adsorção e difusão (LEVINE et al, 1985). Em reatores anaeróbios, as parcelas solúvel e coloidal permanecem, em tese, dentro dos reatores apenas pelo tempo equivalente ao tempo de detenção hidráulica (TDH). A parcela supracoloidal pode, eventualmente, ser capturada pela manta de lodo ou ser adsorvida pelos flocos biológicos, permanecendo no reator por períodos maiores que o TDH. Entretanto, uma vez capturadas pela biomassa, as partículas estarão sujeitas a forças de cisalhamento compatíveis com seu tamanho (MAHMOUD; ZEEMAN; GIJZEN, 2003). A fração sedimentável, por sua vez, pode ficar retida no reator por períodos equivalentes ao tempo de retenção celular, resultando em maior tempo para sua degradação.

O trabalho desenvolvido por Guellil et al (2001) visava ao estudo da transferência de matéria orgânica entre o efluente e a biomassa, 
durante a biosorção. Com essa finalidade, o efluente foi misturado à biomassa e, após um curto período de tempo (menos de 60 minutos), realizou-se um balanço de massa da fase aquosa a partir da caracterização das frações da matéria orgânica (particulada, coloidal e solúvel). Seus resultados mostram que a transferência entre a fração da matéria orgânica e os flocos de biomassa ocorrem em alguns minutos. Em média, 45\% da fração coloidal e solúvel foram removidas durante um curto período de contato com taxas de $14 \mathrm{mg}$ DQO/g SST.min. O estado de equilíbrio da fração coloidal e solúvel foi atingido após 20 e 40 minutos, respectivamente. Os autores admitem que o estado de equilíbrio obtido para a matéria solúvel é mais demorado, uma vez que ocorre a difusão interna da partícula na matriz do floco, limitando, assim, sua etapa de remoção. Mesmo assim, a fração solúvel era sempre transferida do efluente para a biomassa. Já as partículas coloidais não penetram na matriz do floco devido ao seu maior tamanho, permitindo, então, ser aderido ao floco apenas na parte externa, o que reduz o tempo de remoção. Todavia, a fração coloidal era responsável pela ocorrência de desorção da matéria orgânica nos flocos, já que era submetida a forças bidirecionais.

Assim, uma caracterização mais detalhada das partículas de matéria orgânica nos efluentes líquidos é necessária, de modo a possibilitar a otimização das tecnologias de tratamento quanto aos processos de separação sólido-líquido, biológicos e químicos. Além disso, a inclusão de etapas de pré-tratamento, que possibilitam

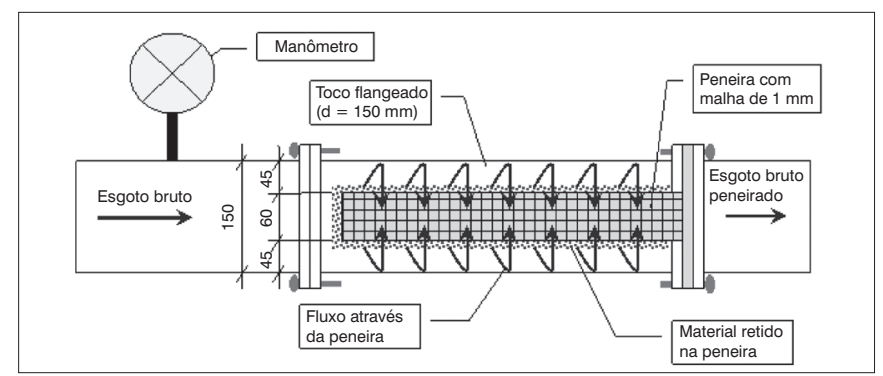

Figura 1 - Esquema da UPF selecionar uma faixa de tamanhos de partículas que oferecem vantagem à cinética do processo biológico de tratamento, pode melhorar o desempenho das unidades de tratamento de esgoto (LEVINE et al, 1991).

\section{Material e métodos}

\section{Unidade de peneiramento forçado}

A unidade de peneiramento forçado (UPF) era constituída por uma adaptação na tubulação de recalque de um conjunto motorbomba, utilizando-se um toco flangeado no qual foi introduzida a peneira metálica. O sistema ainda dispunha de um manômetro que indicava o aumento de pressão, à medida que ocorria a retenção do material sólido durante o tempo de operação. O esgoto bombeado que passava pela UPF havia sido previamente tratado em nível preliminar (gradeamento médio e desarenadores).

A peneira utilizada foi confeccionada e gentilmente cedida pela Prominas Brasil Equipamentos. Apresentava malha com abertura de $1 \mathrm{~mm}$, dificultando, assim, a passagem de sólidos com dimensões maiores. Contudo, o objetivo da peneira não era reter o material particulado contido no esgoto bruto, mas forçar a ruptura das partículas através da sua passagem pelas aberturas da peneira. As Figuras $1 \mathrm{e}$ 2 apresentam, respectivamente, o desenho esquemático e a vista da unidade de peneiramento forçado cujas características são listadas na Tabela 1

Aplicaram-se diferentes vazões ao sistema, conforme indicado na Tabela 2. Vale ressaltar que as vazões eram constantes, sem simulações de variações horárias.

\section{Operação da UPF}

O acúmulo de material retido na peneira ocasionava o aumento da perda de carga e, portanto, o aumento da pressão interna do sistema.
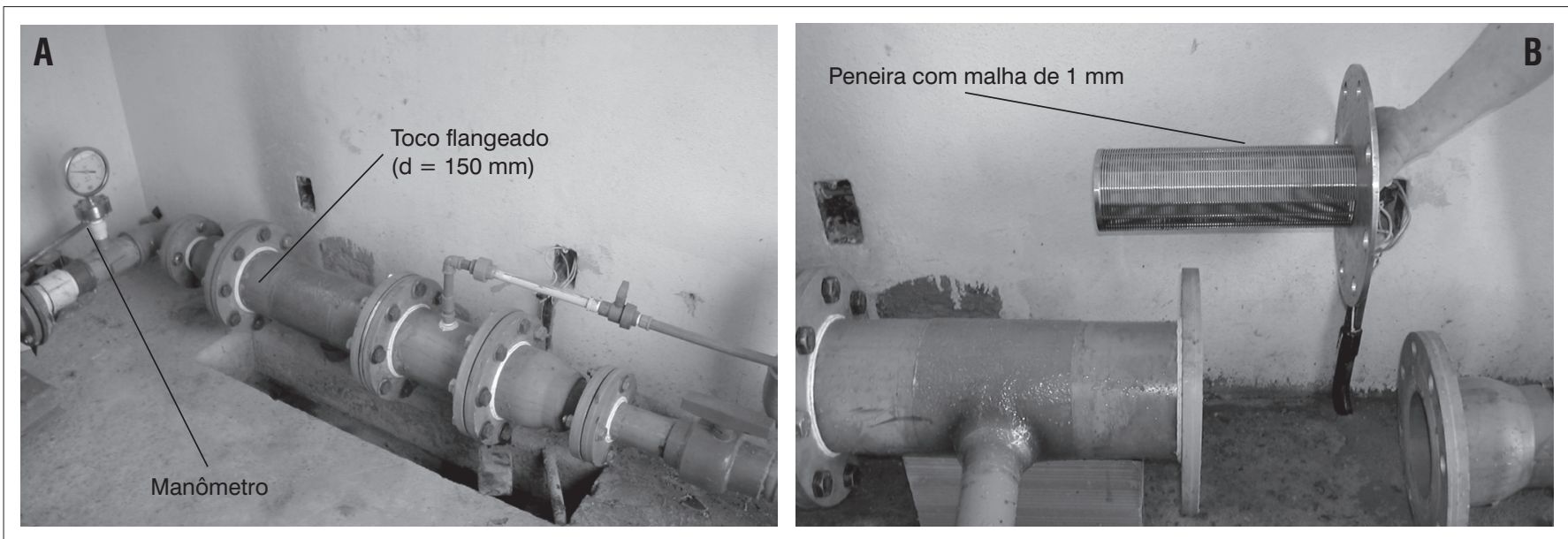

Figura 2 - Vista da UPF: (A) manômetro e toco flangeado que contém a peneira; (B) peneira em aço inox 
Como as peças de ligações da UPF eram em PVC, restringiu-se a pressão máxima de trabalho em $5 \mathrm{kgf} / \mathrm{cm}^{2}$, sendo que o sistema era desativado sempre que o manômetro indicava pressão de $4,5 \mathrm{kgf} / \mathrm{cm}^{2}$.

Testes de pressão antecederam a operação do sistema para escolha da abertura da malha da peneira a ser utilizada ( $1 \mathrm{~mm}$ ou 0,5 mm), como também balizou a frequência de limpeza da unidade. Esses testes visavam a avaliar a variação da pressão e da vazão com o tempo de operação do sistema. A partir dos resultados, apresentados nas Figuras 3 e 4, definiu-se pela utilização da peneira com malha de $1 \mathrm{~mm}$, uma vez que, durante 24 horas ininterruptas de operação, a vazão manteve-se pouco declinante e pouco variável, concomitantemente a um aumento gradual da pressão de 0,5 a 1,0 kgf/ $\mathrm{cm}^{2}$ (Figura 3), caracterizando a situação ideal para operação da UPF. Em contrapartida, a peneira com abertura de malha de 0,5 $\mathrm{mm}$ apresentou resultados que inviabilizam a operação do sistema (Figura 4), atingindo, após seis horas, em média, de funcionamento, a pressão de $4 \mathrm{kgf} / \mathrm{cm}^{2}$ devido à rápida colmatação da malha. Nesse caso, a vazão aplicada $(0,31 \mathrm{~L} / \mathrm{s})$ ainda foi inferior à do teste de pressão com a peneira de malha de $1 \mathrm{~mm}(0,71 \mathrm{~L} / \mathrm{s})$.

Considerando que 24 horas contínuas de operação da UPF causou um aumento na pressão de trabalho de 0,5 kgf/ $\mathrm{cm}^{2}$ (Figura 3), projetou-se a autonomia de funcionamento do sistema para sete dias, quando a pressão atingiria o patamar de $4 \mathrm{kgf} / \mathrm{cm}^{2}$.

\section{Manutenção e limpeza da UPF}

Conforme mencionado anteriormente, os procedimentos de manutenção e limpeza da UPF eram feitos semanalmente. A seguinte rotina era aplicada: paralisação da bomba; retirada dos parafusos do toco flangeado, retirada da peneira (Figura 5); raspagem do material retido com escova de aço; lavagem com água corrente e escova; reintrodução da peneira no interior da peça flangeada; religamento da bomba. A rotina completa de procedimentos durava cerca de 30 minutos.
Tabela 1 - Principais características da UPF

\begin{tabular}{lc} 
Característica & Tipo/valor \\
Material & Aço inoxidável \\
\hline Diâmetro do toco flangeado $(\mathrm{mm})$ & 150 \\
Diâmetro da peneira $(\mathrm{mm})$ & 60 \\
Largura das aberturas $(\mathrm{mm})$ & 1,0 \\
Pressão de trabalho $\left(\mathrm{kgf} / \mathrm{cm}^{2}\right)^{*}$ & 0 a 5 \\
\hline *Estabelecida em função das conexões utilizadas na UPF. &
\end{tabular}

Tabela 2 - Vazões de operação do conjunto motorbomba da UPF

\begin{tabular}{lcc} 
Fases operacionais & Duração (dias) & Vazão média $\left(\mathrm{m}^{3} / \mathrm{h}\right)$ \\
\hline Fase 1 & 70 & 1,53 \\
\hline Fase 2 & 64 & 2,19 \\
Fase 3 & 53 & 3,37 \\
Fase 4 & 271 & 2,80
\end{tabular}

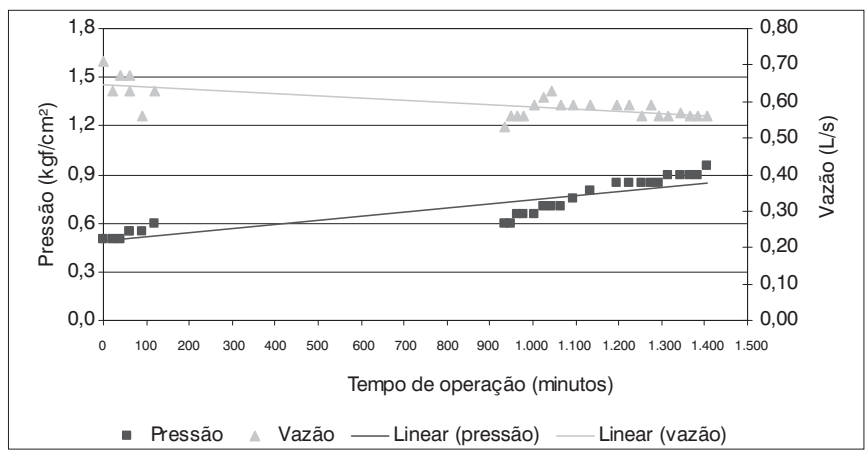

Figura 3 - Teste de pressão utilizando a peneira com malha de $1 \mathrm{~mm}$

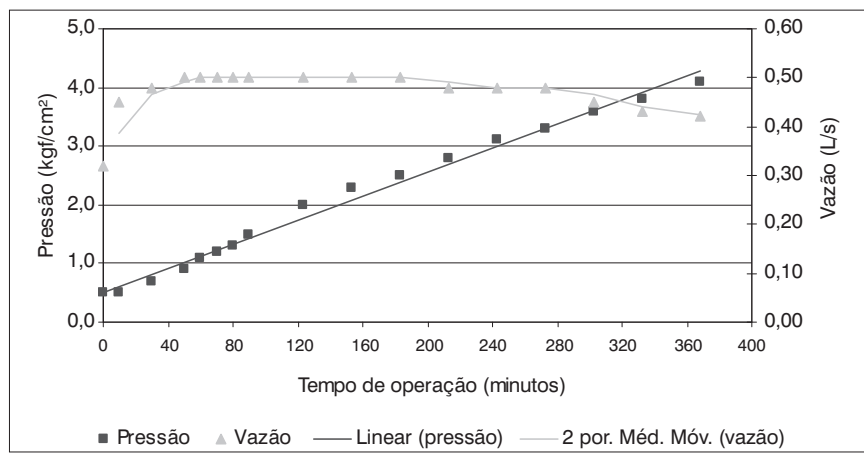

Figura 4 - Teste de pressão utilizando a peneira com malha de $0,5 \mathrm{~mm}$
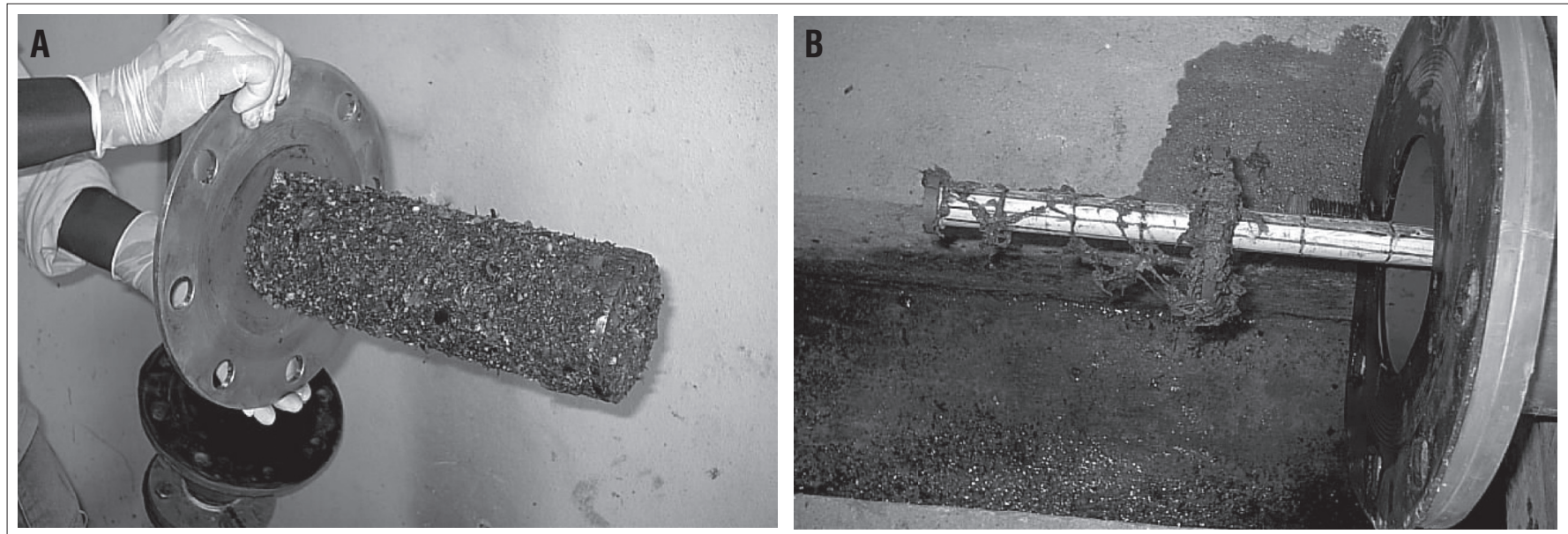

Figura 5 - Procedimento de limpeza da UPF: (A) retirada da peneira metálica para limpeza; (B) vista da peça flangeada após retirada da peneira 
O material sólido removido da peneira era acondicionado em um frasco de plástico e enviado para caracterização físico-química nos laboratórios do Departamento de engenharia Sanitária e Ambiental (Desa) da Universidade Federal de Minas Gerais (UFMG). As análises e métodos empregados para caracterização desse material são descritos a seguir, no item Protocolo de testes.

\section{Estimativa da redução da abertura da malha da peneira}

Durante o funcionamento da unidade, a abertura da malha era reduzida devido à colmatação da peneira pelo material retido. Essa redução da área efetiva foi estimada com base no aumento da perda de carga que correspondia ao aumento da pressão de trabalho, valor anotado diariamente.

A Fórmula Universal da Perda de Carga em condutos forçados circulares é descrita pela Equação 1:

$\mathrm{h}_{f}=f \times \frac{\mathrm{LxV}^{2}}{\mathrm{D} \times 2 \mathrm{xg}}$

Equação 1

onde:

$\mathrm{h}_{\mathrm{f}}$ : perda de carga $(\mathrm{m})$;

f: constante de proporcionalidade (adimensional);

L: extensão do conduto (m);

$\mathrm{V}$ : velocidade $(\mathrm{m} / \mathrm{s})$;

D: diâmetro hidráulico (m);

g: aceleração da gravidade $\left(\mathrm{m} / \mathrm{s}^{2}\right)$.

No caso, não havia alteração da constante de proporcionalidade, da extensão do conduto e do diâmetro hidráulico, podendo, então, esses termos serem representados por uma constante C. Substituindo a velocidade de escoamento pela relação vazão/área e considerando que a perda de carga era correspondente à pressão do sistema, tem-se a expressão:

$P=C \times \frac{Q^{2}}{2 \times g \times A^{2}}$

onde:

P: pressão de trabalho (m);

C: constante que considera f, L e D (adimensional);

Q: vazão $\left(\mathrm{m}^{3} / \mathrm{s}\right)$;

g: aceleração da gravidade $\left(\mathrm{m} / \mathrm{s}^{2}\right)$;

A: área da abertura da malha $\left(\mathrm{m}^{2}\right)$.

Portanto, a área da abertura da malha da peneira, em um tempo T de operação, era dada pela Equação 3 .
$A=Q \times \sqrt{\frac{C}{2 \times g}} \times \frac{1}{\sqrt{P}}$

Equação 3

A redução da abertura da malha da peneira foi, então, estimada pela relação:

$\frac{\mathrm{A}_{\mathrm{T}}}{\mathrm{A}_{\mathrm{T} 0}}=\sqrt{\frac{\mathrm{P}_{\mathrm{T} 0}}{\mathrm{P}_{\mathrm{T}}}}$

Equação 4

onde:

$\mathrm{A}_{\mathrm{T}}$ : área da abertura da peneira, em um tempo de operação T;

$\mathrm{A}_{\mathrm{TO}}$ : área da abertura da peneira, em um tempo de operação $\mathrm{T}_{0}$;

$\mathrm{P}_{\mathrm{T}}$ : pressão de trabalho, em um tempo de operação $\mathrm{T}$;

$\mathrm{P}_{\mathrm{TO}}$ : pressão de trabalho, em um tempo de operação $\mathrm{T}_{0}$.

\section{Protocolo de testes}

\section{Distribuição de tamanho de partículas}

Os ensaios de distribuição de tamanho de partículas (DTP) foram realizados quinzenalmente com os esgotos bruto e bruto peneirado. Para obtenção da DTP, utilizou-se um granulômetro (modelo Helos Sympatec $^{\circledR}$ ) de difração a laser, gentilmente cedido pelo Departamento de Engenharia de Minas da Escola de Engenharia (EE-UFMG), capaz de fornecer uma curva de DTP na faixa de 1,8 a $350 \mu \mathrm{m}$

\section{Fracionamento da demanda química de oxigênio}

O fracionamento da demanda química de oxigênio (DQO) foi feito por meio de filtração das amostras em membrana de fibra de vidro, porosidade de 1,2 $\mu \mathrm{m}$, de forma a possibilitar a avaliação das parcelas filtrada e particulada. Dessa forma, realizaram-se análises de DQO total e filtrada dos esgotos bruto e bruto peneirado. As análises foram realizadas de acordo com os procedimentos descritos no Standard Methods for the Examination of Water and Wastewater (AWWA/APHA/ WEF, 1998). As amostras eram compostas em 24 horas, coletadas duas vezes por semana, a montante e a jusante da UPF.

\section{Caracterização do material retido na unidade de peneiramento forçado}

A caracterização química do material retido na peneira foi feita semanalmente, durante as duas primeiras fases da pesquisa, com uma amostra do resíduo obtido durante a limpeza da peneira. Inicialmente, era feita a quantificação total de volume e massa do material sólido retido, utilizando-se um becker graduado (volume de $500 \mathrm{~mL}$ ) e uma balança analítica, respectivamente. Então, uma amostra representativa do material removido era submetido a um pré-tratamento para a sua homogeneização, que consistia em triturar o material in natura em um processador de alimentos - Black $\mathcal{E}$ Decker, $310 \mathrm{~mL}$ de capacidade e $150 \mathrm{~W}$ de potência. A amostra pastosa foi analisada também de acordo com o Standard methods for the 
examination of water and wastewater (AWWA/APHA/WEF, 1998), para os seguintes parâmetros: DQO, ST e STV.

Efetuaram-se, ainda, testes de biodegradabilidade aeróbia e anaeróbia do material. A análise de biodegradabilidade aeróbia baseou-se em testes de $\mathrm{DBO}_{5}$ e $\mathrm{DBO}_{20}$ e o resultado de $\mathrm{DBO}$ obtido, dividido pela concentração de DQO, forneceram a biodegradabilidade aeróbia de 5 e 20 dias, respectivamente.

A biodegradabilidade anaeróbia foi determinada utilizando-se um procedimento modificado de Owen et al. (1979). Frascos de vidro de $110 \mathrm{~mL}$ foram purgados com nitrogênio e inoculados com $15 \mathrm{~mL}$ de lodo anaeróbio (retirado da manta de lodo de um reator UASB), $5 \mathrm{~mL}$ do material retido na peneira e $60 \mathrm{~mL}$ de solução de nutrientes, composta de fósforo, nitrogênio, ferro, enxofre, traços de metais e fonte de alcalinidade, utilizada nos testes de Atividade Metanogênica Específica (AME), conforme descrito por Souto et al. (2007). Os frascos eram lacrados com septo de borracha que permitia a determinação da produção e amostragem de biogás aferida por meio de seringa de vidro esmerilhada. A determinação da composição do biogás foi feita por cromatografia gasosa. A biodegradabilidade anaeróbia foi, então, calculada com base na produção real de metano e na produção teórica, obtida a partir do conhecimento a respeito da massa de DQO incubada ( $1 \mathrm{~g} \mathrm{DQO} \approx 394 \mathrm{~mL} \mathrm{CH}_{4}$ a $30{ }^{\circ} \mathrm{C}$ e $\left.1 \mathrm{~atm}\right)$

\section{Análises estatísticas}

Visando a comparar a igualdade da tendência central dos parâmetros analisados dos esgotos bruto e bruto peneirado, foram realizados testes de hipótese por meio do programa computacional Statistica, versão 6.1. O programa gera como resultado o valor de p que deve ser maior que (1- $\alpha)$, sendo $\alpha$ o intervalo de confiança, para que a hipótese seja aceita. Adotou-se o intervalo de confiança de 95\%.

Como não foi possível garantir se as amostras seguiam uma distribuição normal, associados ao pequeno número de dados disponibilizados, aplicaram-se testes não-paramétricos, escolhidos conforme o conjunto amostral analisado. Para se avaliarem diferenças nas médias observadas entre dois grupos de amostras dependentes ou pareadas, que abrangem os resultados dos esgotos bruto e bruto peneirado, foi aplicado o teste $t$ de Wilcoxon.

O teste de Mann-Whitney, também conhecido como teste U de Mann-Whitney, compara tendências centrais de duas amostras independentes que, nesse caso, refere-se aos resultados obtidos, para o mesmo tipo de efluente, durante duas fases operacionais distintas. Já o teste não-paramétrico de Kruskal-Wallis ANOVA e o teste de medianas foram utilizados para se verificar a existência de diferenças significativas entre os resultados medianos obtidos nas diferentes fases operacionais. Quando os resultados obtidos são considerados diferentes pelos testes Kruskal-Wallis ANOVA e teste de medianas, podem ser empregados os testes de comparações múltiplas de classes para todos os grupos. Esses testes permitem uma comparação simultânea entre todos os resultados obtidos, além da verificação de quais fases apresentaram desempenhos diferenciados.

\section{Resultados e discussão}

Os resultados apresentados na Figura 6 confirmam a eficiência da UPF na redução do tamanho de partículas contidas no esgoto bruto durante as duas primeiras fases da pesquisa. Para ambas as fases, houve um aumento da porcentagem de partículas com diâmetros inferiores a $30 \mu \mathrm{m}$ e consequente diminuição da porcentagem de partículas com diâmetros maiores que $50 \mu \mathrm{m}$. Essas diferenças entre a granulometria dos sólidos presentes no esgoto bruto e no esgoto bruto peneirado são confirmadas pelos testes estatísticos (testes $t$ de Wilcoxon), que negaram a hipótese de igualdade dos dados entre as faixas de 1,8 a $30 \mu \mathrm{m}$ e de 50 a $206 \mu \mathrm{m}$.

Para comparar a variância dos resultados obtidos nas duas fases estudadas, o teste não-paramétrico aplicado foi o de Mann-Whitney, já que se trata de dados independentes. As análises estatísticas levam a crer que a DTP do esgoto bruto peneirado, quando submetido às diferentes condições operacionais avaliadas, não diferem. Ou seja, há indícios que o acréscimo de cerca de 70\% na vazão da bomba não tenha alterado a DTP do esgoto bruto peneirado. Ademais, como os testes estatísticos também não indicaram variações da DTP do esgoto bruto durante as duas fases, tal premissa tende a ser validada.

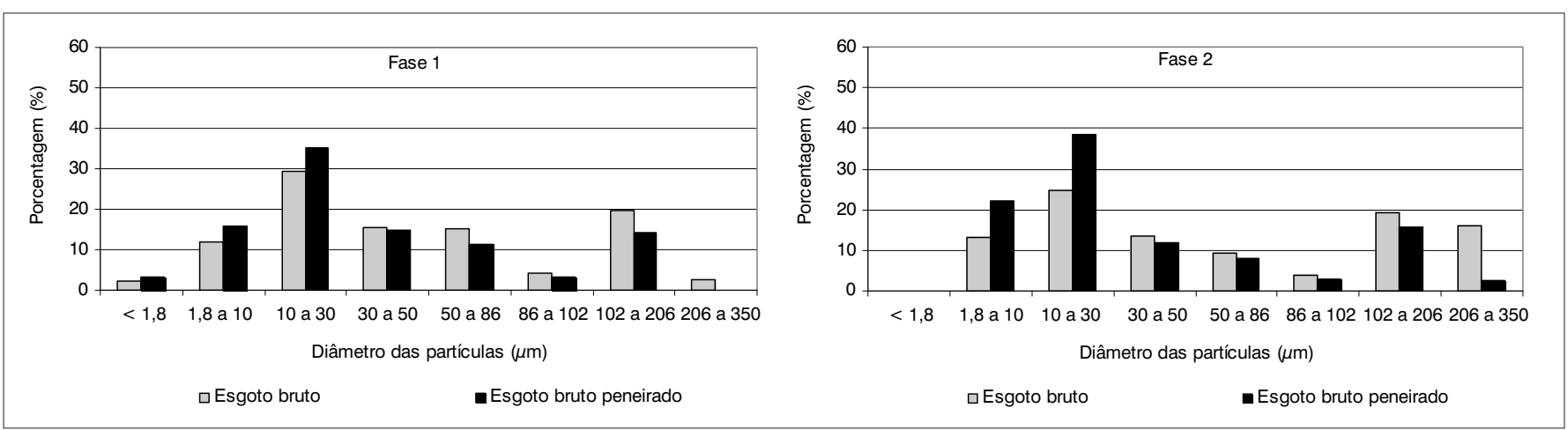

Figura 6 - Valores medianos $(n=5)$ da DTP dos esgotos bruto e bruto peneirado 


\section{Estimativa da redução da abertura da malha da peneira}

A evolução da redução média da abertura da malha da peneira, em relação à abertura inicial $\left(\mathrm{A}_{\mathrm{TO}}\right)$ de $1 \mathrm{~mm}$, durante o período de operação da unidade é apresentada na Figura 7.

Nota-se que, quando a UPF foi operada com vazões maiores (Fase 3), o sistema apresentou evolução maior da perda de carga e, consequentemente, uma redução média de $27 \%$ no final do tempo de operação da unidade, que correspondia a uma malha com abertura efetiva de $0,73 \mathrm{~mm}$. Já operando com vazão de $1,53 \mathrm{~m} 3 / \mathrm{h}$ (Fase 1), a redução média foi de apenas 14\%, apresentando, no último dia de operação, abertura efetiva da malha de 0,86 mm. Nas Fases 2 e 4, a abertura efetiva final foi, em média, de 0,79 e 0,77 mm, respectivamente. Cabe ressaltar que, como discutido anteriormente, as vazões de operação pouco interferiram na DTP, quando avaliados os resultados obtidos das análises granulométricas dos esgotos bruto e bruto peneirado nas Fases 1 e 2. Desse modo, é possível inferir que o aumento da vazão aplicada à

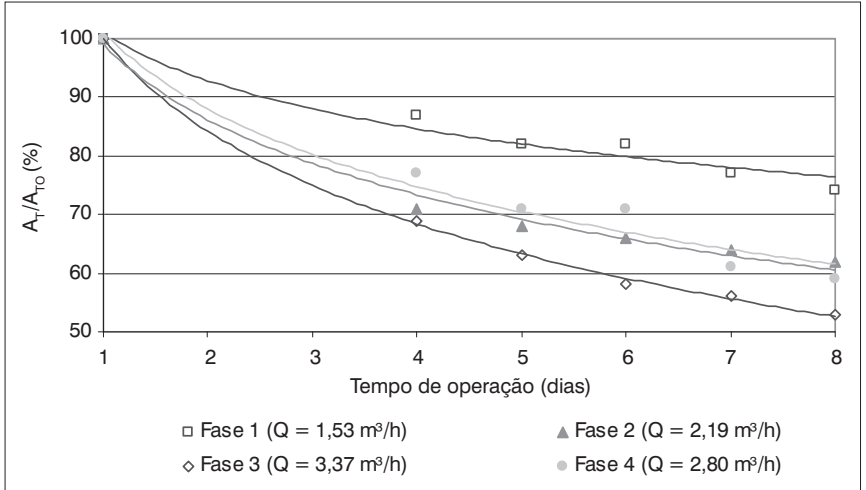

Figura 7 - Redução estimada da abertura da malha da peneira durante 0 período de operação da UPF
UPF diminui a abertura efetiva da malha da peneira devido ao acúmulo de material retido, porém tal redução não altera a DTP do esgoto bruto, incidindo somente no aumento da perda de carga e, consequentemente, no menor tempo de operação da unidade.

Ademais, a redução do tamanho médio das partículas na faixa de 1,8 a $100 \mu \mathrm{m}$ foi muito superior à abertura estimada da malha após sua colmatação. Isso indica que o acúmulo do resíduo na peneira permite que a 'quebra' das partículas seja de magnitude maior do que a imposta pela abertura inicial da malha, independentemente da vazão aplicada à UPF.

\section{Análise comparativa do fracionamento da DQO dos esgotos bruto e peneirado}

A Figura 8 apresenta um gráfico de barras que retrata os resultados medianos da composição da DQO do esgoto bruto (EB) e do esgoto bruto peneirado (EBp). A altura total da barra corresponde à concentração total de DQO, enquanto as partes hachurada e sem cor representam, respectivamente, as parcelas particulada e filtrada da DQO. Vale ressaltar que, como a UPF foi operada sob diferentes condições de vazões e as fases ocorreram em diferentes épocas do ano, optou-se por apresentar os dados diferenciados conforme as fases da pesquisa.

Os testes estatísticos aqui empregados foram o teste $t$ de Wilcoxon, quando comparados os esgotos bruto e bruto peneirado, e o teste de Kruskal-Wallis ANOVA, no caso de se avaliarem as possíveis diferenças ocorridas nas concentrações de DQO dos efluentes sob as diferentes condições operacionais ou sazonalidades.

Por meio da análise do gráfico, verifica-se que, durante todas as fases operacionais, não ocorreram diferenças substanciais das concentrações totais de DQO entre os esgotos bruto e bruto peneirado,

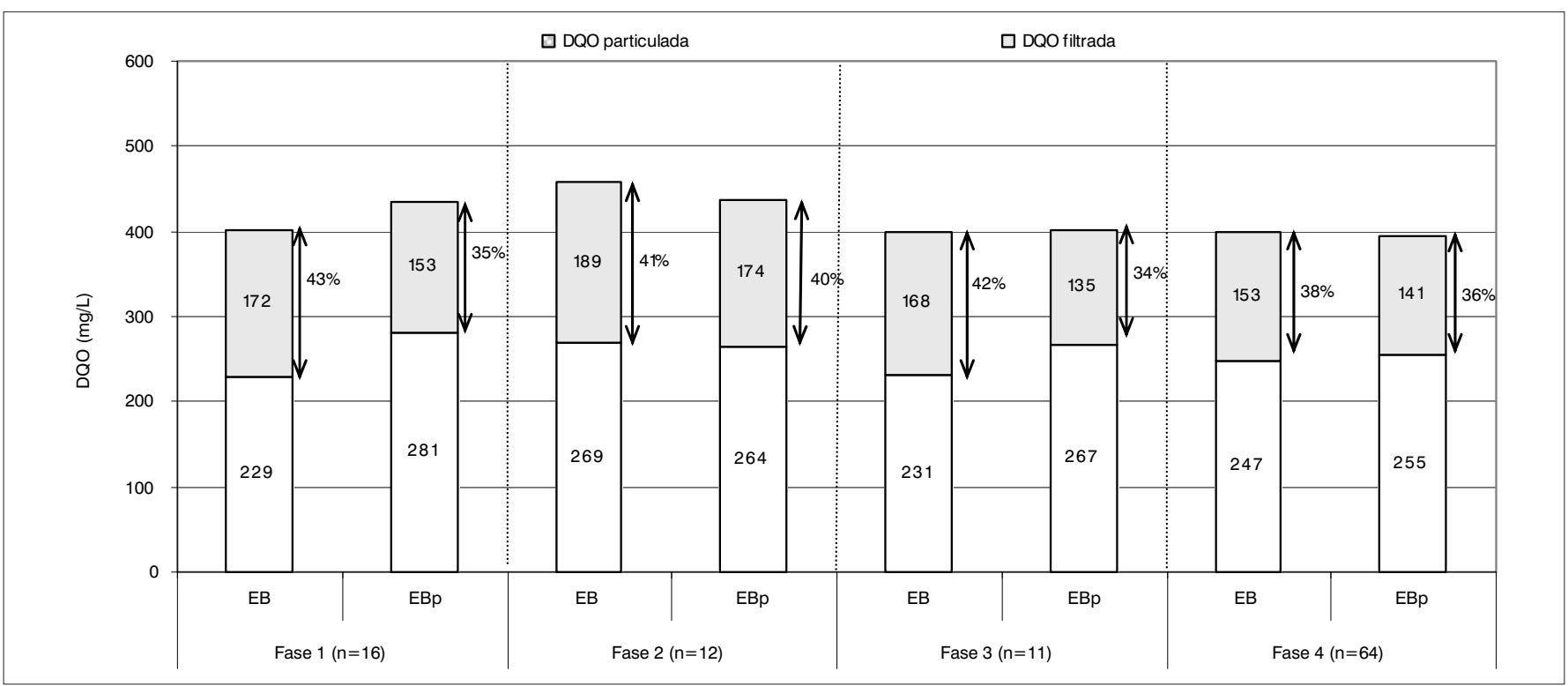

Figura 8 - Composição da DQO dos esgotos bruto e bruto peneirado 
assim como mostra também o gráfico Box e Wisker (Figura 9), o que nos leva a inferir que a UPF pouco influenciou na redução/retenção de $\mathrm{DQO}_{\text {TOTAL }}$. Esses resultados procedem quando aplicados, para cada fase, os testes de hipótese, que não indicaram diferenças entre os valores da concentração de $\mathrm{DQO}_{\text {TOTAL }}$ dos esgotos bruto e bruto peneirado. Portanto, a peneira não reteve o material particulado. Cabe ressaltar que a principal função da UPF era reduzir o tamanho das partículas; tal objetivo foi alcançado.

Outro ponto a ser destacado na Figura 8 refere-se à diferença na concentração mediana de $\mathrm{DQO}_{\text {TOTAL }}$ dos esgotos bruto e bruto peneirado, na Fase 1, possivelmente ocasionada pela grande variabilidade dos dados, como mostra o gráfico da Figura 9.
A concentração mediana da parcela filtrada da DQO mostrou-se ligeiramente inferior no esgoto bruto peneirado, mas a diferença da tendência central da concentração de $\mathrm{DQO}_{\text {FILTRADA }}$ entre os esgotos bruto e bruto peneirado só foi confirmada estatisticamente nas Fases 3 e 4 . Vale lembrar que os testes estatísticos são conservadores quando se trata de negar a hipótese, principalmente quando o conjunto amostral apresenta poucos dados e grande variabilidade, como é o caso dos dados das Fases 1 e 2 (gráfico Box e Whisker, Figura 10).

A diferença na concentração de $\mathrm{DQO}_{\text {FILTRADA }}$ entre os esgotos bruto e bruto peneirado obtida na Fase 3 foi superior à concentração das demais fases, o que pode ser justificado pela elevada vazão de operação da unidade (Fase $3-3,37 \mathrm{~m}^{3} / \mathrm{h}$ ). Pela análise visual da série

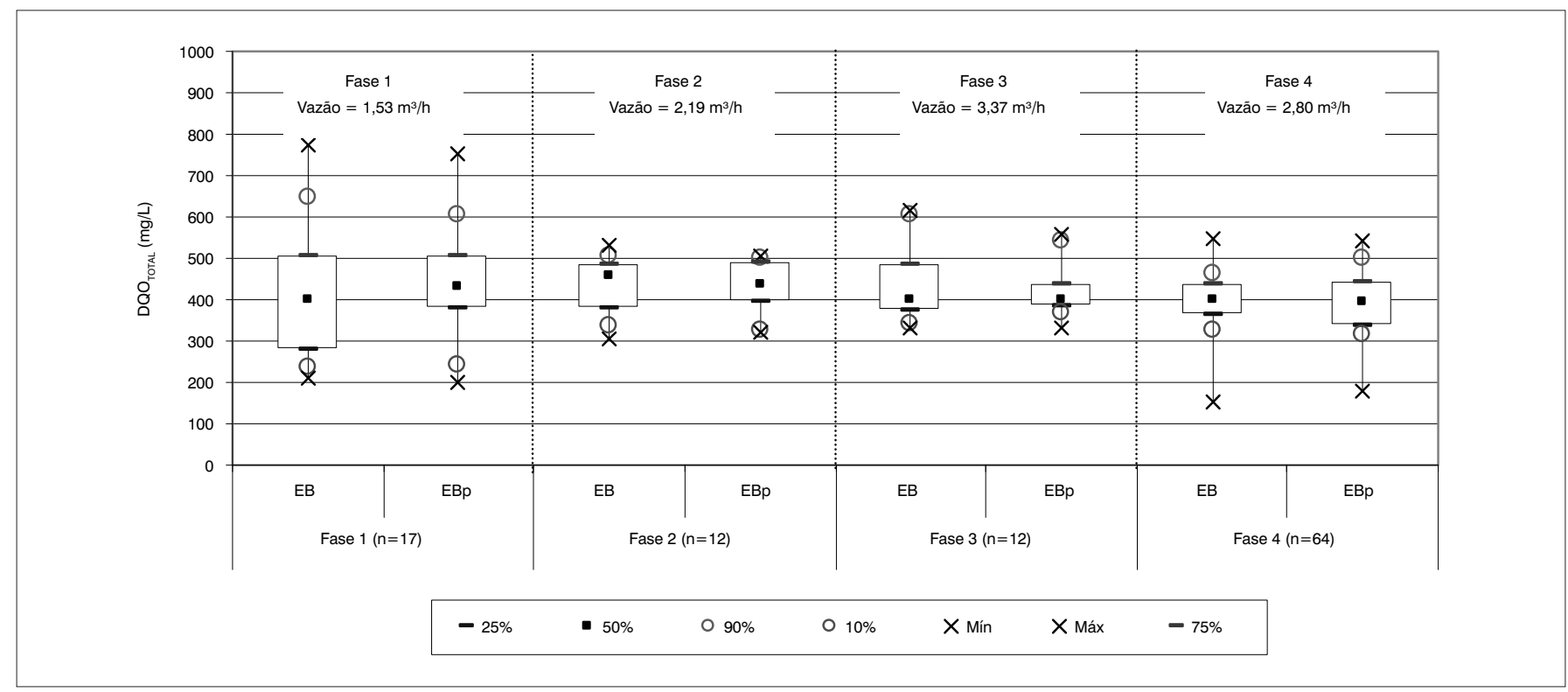

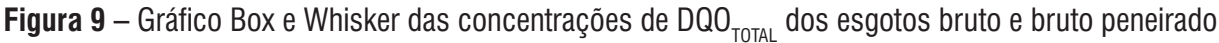

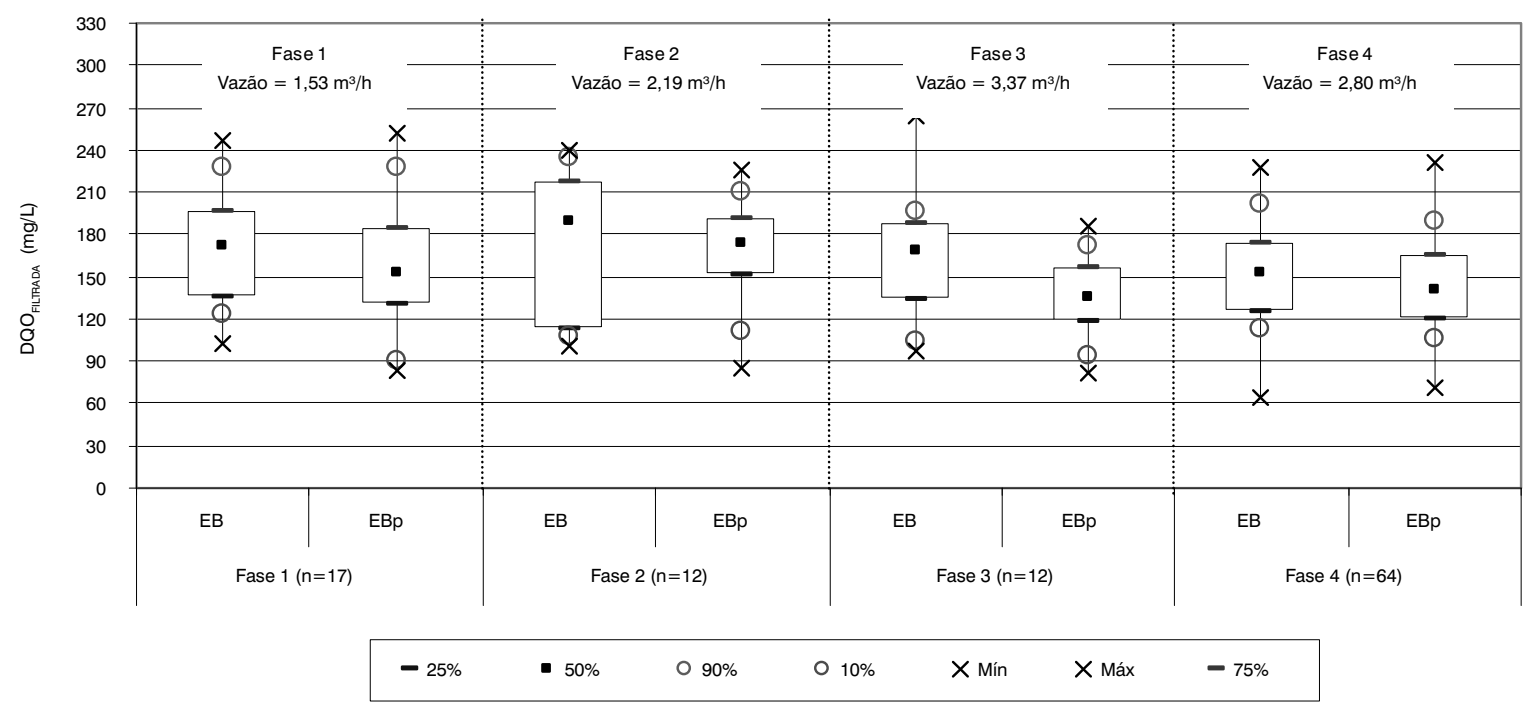

Figura 10 - Gráfico Box e Whisker das concentrações de DQO ${ }_{\text {FILTRADA }}$ dos esgotos bruto e bruto peneirado 


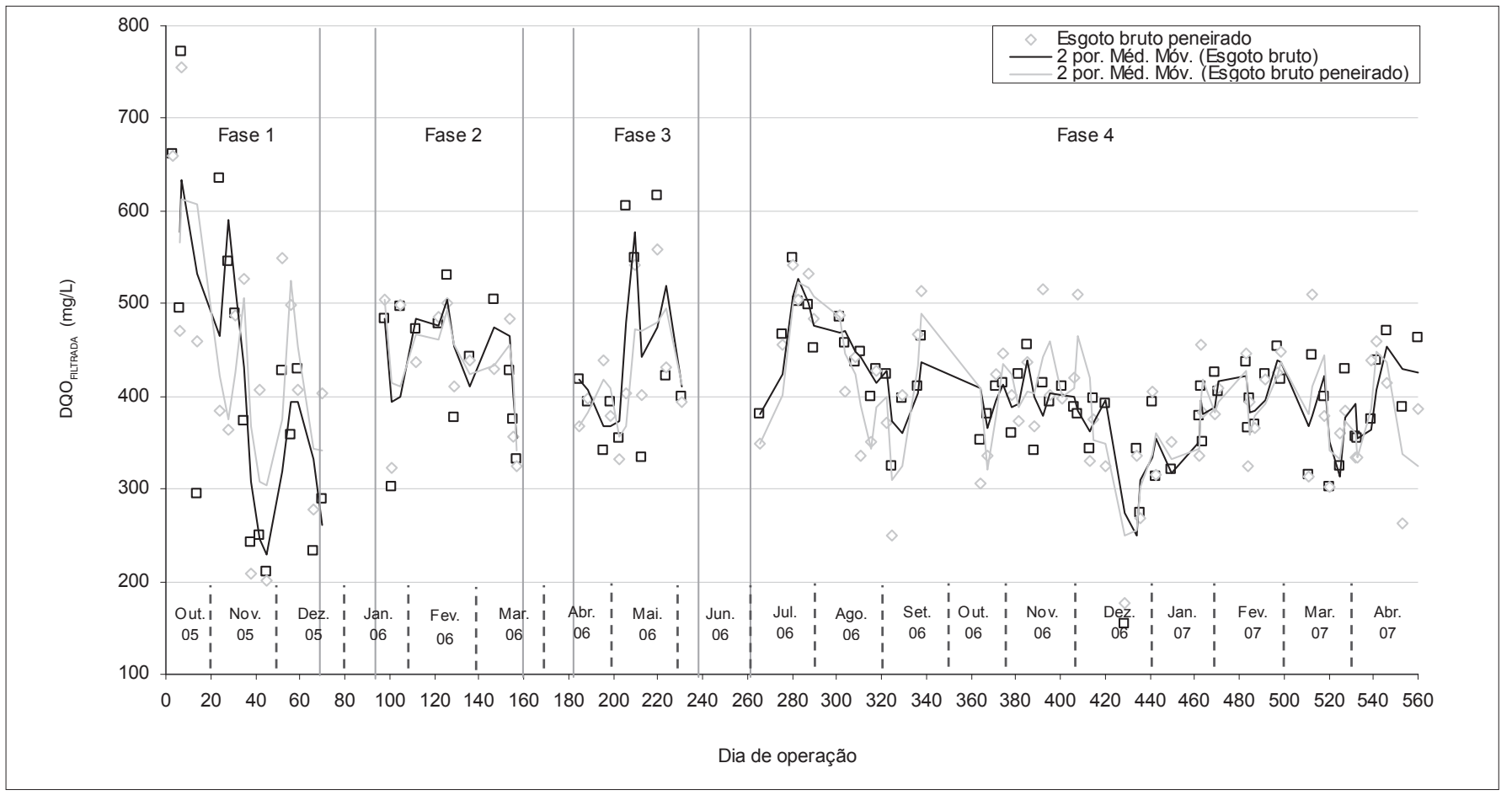

Figura 11 - Série histórica dos resultados de DQO ${ }_{\text {FLTRADA }}$ do esgoto bruto

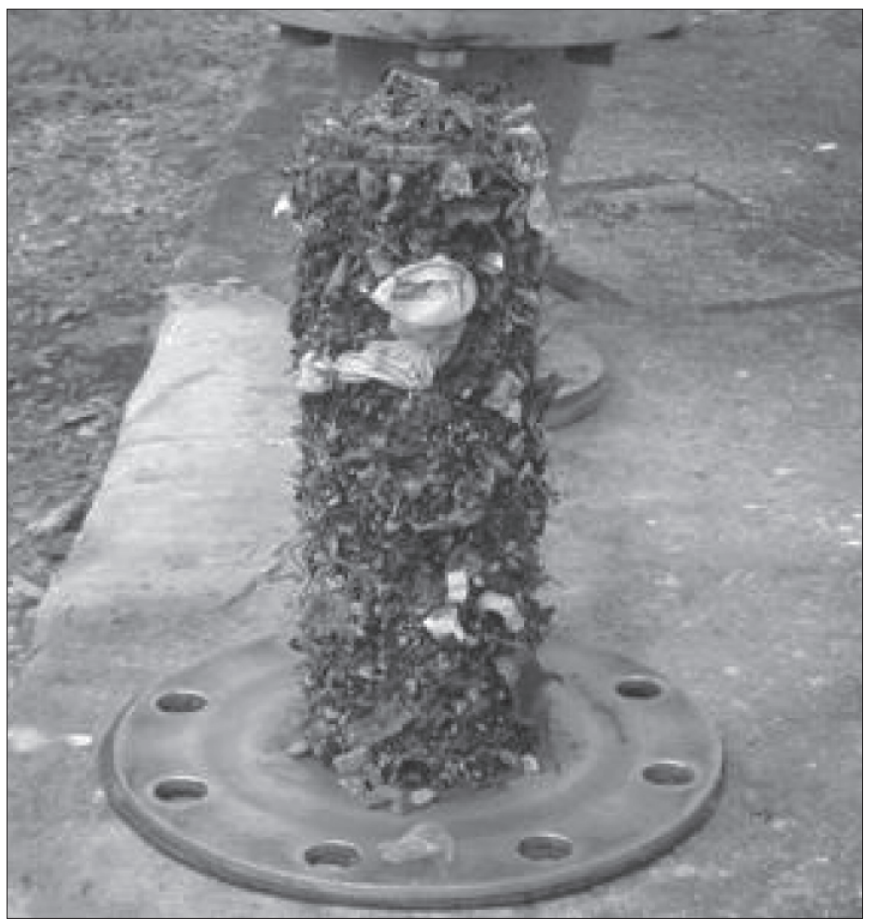

Figura 12 - Material retido na peneira

histórica dos dados de $\mathrm{DQO}_{\text {FILTRADA }}$ dos efluentes (Figura 11), essa informação se confirma uma vez que a linha de tendência traçada para os dados de $\mathrm{DQO}_{\text {FILTRADA }}$ do esgoto bruto peneirado localiza-se abaixo da linha do esgoto bruto, durante toda a Fase 3. O comportamento das demais fases é bem semelhante, com maiores concentrações da parcela filtrada de DQO variando entre os dois efluentes.
Não deveria existir diferença entre o esgoto bruto e bruto peneirado quanto à concentração da parcela filtrada de DQO, uma vez que a UPF 'produziu' sólidos particulados na faixa de 1,8 a $30 \mu \mathrm{m}$, que ainda são maiores que a porosidade do filtro utilizado na análise. Porém, a questão levantada pela análise realizada foi que a UPF possa diminuir a concentração de $\mathrm{DQO}_{\text {FILTRADA }}$ do esgoto bruto, sendo mais significante quanto maior for a vazão aplicada. Uma das justificativas é que a amostra do esgoto bruto peneirado possa ser mais representativa, já que o efluente apresentava sólidos com dimensões menores que poderiam ser pipetados e contabilizados nas análises de DQO.

\section{Quantificação e caracterização do material retido na UPF}

Durante a coleta do resíduo da peneira, foi possível fazer uma caracterização visual do material, e observou-se a presença dos seguintes materiais: casca de legumes e frutas, cabelos, papel, plástico, sementes, partes de insetos, barbantes e pedaços de sólidos não identificados. Segundo o processo classificatório de resíduos sólidos definidos pela Associação Brasileira de Normas Técnicas (ABNT, 2004), o material retido na peneira pode ser classificado como Resíduo Perigoso Classe I por apresentar risco à saúde pública, provocando mortalidade, incidência de doenças ou acentuando seus índices além de risco ao meio ambiente, quando gerenciado de forma inadequada. A Figura 12 apresenta uma foto da peneira com o material retido. 
Tabela 3 - Resultados médios das análises químicas do material retido na peneira

\begin{tabular}{|c|c|c|c|c|c|c|c|}
\hline \multirow{2}{*}{\multicolumn{2}{|c|}{ Parâmetro }} & \multicolumn{6}{|c|}{ Concentração } \\
\hline & & $\mathrm{n}^{*}$ & Média & Mediana & Mínimo & Máximo & Desvio padrão \\
\hline \multicolumn{2}{|l|}{$\mathrm{DQO}_{\text {TOTAL }}(\mathrm{g} / \mathrm{L})$} & 13 & 106 & 88 & 18 & 226 & 70 \\
\hline \multicolumn{2}{|c|}{ Sólidos totais - ST (g/L) } & 12 & 123 & 130 & 47 & 193 & 44 \\
\hline \multicolumn{2}{|c|}{ Sólidos totais voláteis - STV (g/L) } & 12 & 76 & 71 & 28 & 158 & 35 \\
\hline \multirow{2}{*}{$\begin{array}{l}\text { Biodegradabilidade } \\
\text { aeróbia (\%) }\end{array}$} & 5 dias & 1 & 8,9 & - & - & - & - \\
\hline & 20 dias & 1 & 11,8 & - & - & - & - \\
\hline \multirow{2}{*}{$\begin{array}{l}\text { Biodegradabilidade } \\
\text { anaeróbia (\%) }\end{array}$} & 5 dias & 1 & 11,1 & - & - & - & - \\
\hline & 20 dias & 1 & 29,0 & - & - & - & - \\
\hline
\end{tabular}

* Número de dados.

Tabela 4 - Carga orgânica afluente e retida na peneira

$\begin{array}{lccc}\text { Parâmetro } & \text { Carga orgânica afluente* }(\mathrm{kg} / \text { dia }) & \text { Carga retida }(\mathrm{kg} / \text { dia) } & \text { Porcentagem do material retido (\%) } \\ \text { DQO }_{\text {TOTAL }} & 21,6 & 0,005 & 0,02 \\ \text { DQO }_{\text {PARTICULADA }} & 12,6 & 0,005 & 0,04\end{array}$

*A carga orgânica afluente (kg/dia) foi baseada na mediana dos resultados de DQO das fases 1 e 2 ( $n=28)$.

A produção média de material retido em sete dias de operação foi

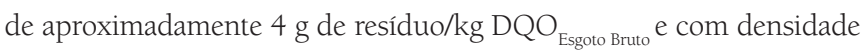
média do material solto de 0,88 g/mL. As Tabelas 3 e 4 apresentam, respectivamente, os resultados médios dos testes de caracterização química do material retido e os valores de alguns parâmetros calculados.

Os resultados apresentados na Tabela 3 comprovam que o material retido na peneira é predominantemente orgânico (STV/ST = $0,62)$ e não estabilizado, o que resultou em elevadas concentrações de DQO. Os resultados de biodegradabilidade sugerem que o material retido é de difícil biodegradabilidade aeróbia e anaeróbia e que a fração biodegradável é mais bem degradada anaerobiamente do que aerobiamente.

A Tabela 4 mostra que o material orgânico retido na peneira representa 0,04 e 0,02\% da DQO total e particulada, respectivamente, afluentes à unidade de peneiramento. Isso indica que a retenção de sólidos na peneira, em termos de DQO, foi insignificante, confirmando que a UPF apenas alterou a distribuição do tamanho médio das partículas.

Vale ressaltar que não houve diferença entre os resultados obtidos nas diferentes fases operacionais, inferindo que a mudança no controle da vazão de passagem pela peneira não implica em mudanças na constituição do material retido.

\section{Conclusões}

A UPF possibilitou a redução da distribuição do tamanho de partículas presentes no esgoto bruto, na faixa de 1,8 a $100 \mu \mathrm{m}$, aumentando a porcentagem de partículas com diâmetros inferiores a $30 \mu \mathrm{m}$, confirmando, assim, a hipótese levantada. Todavia, a UPF não influenciou na redução/retenção de $\mathrm{DQO}_{\text {TOTAL }}$ do esgoto bruto. Vale ressaltar que os sólidos 'quebrados' durante o peneiramento apresentaram dimensões ainda superiores a 1,2 $\mu \mathrm{m}$ e a redução do tamanho das partículas é desejada para se acelerar o grau de hidrólise e as taxas de conversões metabólicas no reator anaeróbio, o que não deve provocar, necessariamente, alterações da relação DQO $_{\text {FILTRADA }}{ }^{\prime}$ $\mathrm{DQO}_{\text {PARTICULADA }}$

A retenção diária dos sólidos na peneira foi em média de $4 \mathrm{~g}$ de resíduo/kg DQOesgoto bruto com densidade média de 0,88 g/mL (base úmida). A carga orgânica característica do material retido na peneira é de $120 \mathrm{mg}$ DQO/g resíduo. O resíduo da peneira apresentou considerável quantidade de matéria orgânica, haja vista a relação STV/ ST (62\% em média), embora seja um resíduo de difícil biodegradabilidade aeróbia e anaeróbia. Há ressalva da dificuldade de tratar com este resíduo, uma vez que se trata de um material heterogêneo, com frações de elevadas dimensões, de pouca ou lenta biodegradabilidade, não contabilizadas nas análises físico-químicas.

Embora a UPF tenha se mostrado efetiva na redução da distribuição do tamanho das partículas do esgoto bruto, reduzindo substancialmente o tamanho das partículas em relação à abertura da malha da peneira, outras técnicas deveriam ser avaliadas na sua implantação em estações em escala real, tendo em vista as dificuldades operacionais desse tipo de dispositivo, a exemplo da limpeza e controle de pressão.

\section{Agradecimentos}

Os autores agradecem aos órgãos fomentadores: Financiadora de Estudos e Projetos/ Programa de Pesquisas em Saneamento Básico (Finep/Prosab), Conselho Nacional de Desenvolvimento Científico e Tecnológico (CNPq) e Fundação de Amparo à Pesquisa do Estado de Minas Gerais (Fapemig) pelo financiamento da pesquisa; à Companhia de Saneamento de Minas Gerais (Copasa MG) pelo espaço cedido para a implantação do aparato experimental, e à Prominas Brasil Equipamentos por confeccionar e ceder gentilmente as peneiras metálicas usadas no estudo. 


\section{Referências}

ASSOCIAÇÃO BRASILEIRA DE NORMAS TÉCNICAS (ABNT). NBR 10004: Resíduos sólidos - Classificação. Rio de Janeiro, 2004.

AWWA/APHA/WEF. Standard methods for the examination of water and wastewater. 20ae edition. Washington DC: APHA, 1998.

GUELLIL, A. et al Transfer of organic matter between wastewater and active sludge flocs. Water Research, v. 35, n. 1, p. 143-150, 2001.

HENZE, M. et al A general model for single-sluge wastewater treatment systems. Water Research, v. 21, n. 5, p. 505-515, 1987.

$\mathrm{HU}, \mathrm{Z}$. et al Evaluation a rapid physical-chemical method for the determination extant soluble COD. Water Research, v. 36, n. 3, p. 617624, 2002.

LEVINE, A.D.; TCHOBANOGLOUS, G.; ASANO, T. Size distribution of particulate contaminants in wastewater and their impact on treatability.
Water Research, v. 25, n. 8, p. 911-922, 1991.

Characterization of the size distribution of contaminants in wastewater: treatment and reuse implications. Journal Water Pollution Control Federation, v. 57, n. 7, p. 805-816, 1985.

MAHMOUD, N. et al Solids removal in upflow anaerobic reactors, a review. Bioresearch Technology, v. 90, n. 1, p. 1-9, 2003.

SOUTO, T.F.S.; AQUINO, S.F.; CHERNICHARO, C.A.L. Avaliação da influência das condições de incubação no Teste de Atividade MetanogênicaEspecífica (AME) delodosanaeróbios. In:24 CONGRESSO BRASILEIRO DE ENGENHARIA SANITÁRIA E AMBIENTAL, Anais... Belo Horizonte, 2007.

OWEN, W.F.; STUKEY, D.C. Bioassay for monitoring biochemical methane potential and anaerobic toxicity. Water Research, v. 13, n. 6, p. 485-492, 1979. 